\title{
El voto de los residentes en el extranjero. Enseñanzas del derecho comparado
}

\section{Pablo Santolaya*}

\section{Sumario:}

I. Premisas del trabajo

II. Un breve panorama de derecho comparado con algunas cuestiones a considerar

III. En particular, el caso español. La rectificación de un modelo "de máxima generosidad"

IV. La respuesta del ordenamiento jurídico mexicano

V. Conclusión: algunos elementos para su reforma basados en la experiencia del derecho comparado

* Vocal catedrático de la Junta Electoral Central Española.pablo.santolaya@uah.es. 


\section{Premisas del trabajo}

\section{El carácter no universal ni necesario del derecho de sufragio de los nacionales residentes en el extranjero}

El punto de partida de un trabajo sobre el derecho de sufragio de los nacionales residentes en el extranjero debe ser la constatación de que su reconocimiento no es, en forma alguna, una condición para la existencia de unas elecciones libres y justas, ni una consecuencia necesaria del principio indiscutible de la universalidad del sufragio. ${ }^{1}$ No es correcto, en consecuencia, su consideración como un horizonte necesario a alcanzar en el proceso de universalización del derecho, al modo en el que lo fue la eliminación del sufragio censitario a lo largo del siglo XIX o la extensión del sufragio femenino en el XX. No es una meta "ni evidente por sí misma ni exenta de problemas".

De manera que, si bien es cierto que hay una creciente tendencia, a partir de la década de los noventa del siglo pasado, a establecer este tipo de sufragio, sin embargo se hace con un contenido muy variable en relación con el prototipo de elecciones a las que afecta, sus destinatarios, los requisitos exigidos, y, en definitiva, su generalidad. Además, no han faltado experiencias negativas, lo que ha provocado marchas atrás en su reconocimiento. No es un movimiento uniforme y siempre en la misma dirección, sino que, por el contrario, en ocasiones el legislador modifica esos procedimientos y restringe supuestos avances anteriores, quizá precipitados o no lo suficientemente debatidos, que la experiencia ha demostrado puede originar fraudes o manipulaciones o que sencillamente no han alcanzado el resultado que se proponían, acaso por su deficiente diseño. ${ }^{3}$

1 Véase en relación con este planteamiento Del Toro Huerta, Mauricio Iván y De Icaza Hernández, Gerardo, El voto migrante; la tendencia internacional y nacional del voto en el extranjero, en http://biblio.juridicas.unam.mx/libros/6/2993/15.pdf.

2 Nohlen, Dieter y Grotz, Florián, "Marco legal y panorama de la legislación estatal", en Voto en el extranjero. Manual de IDEA Internacional, IDEA-IFE, 2008, en http://www. idea.int/publications/voting_from_abroad/sp.cfm.

Véase además del caso español, las rectificaciones del procedimiento francés tanto a la posibilidad del voto por correspondencia como del voto por delegación de los franceses residentes en el extranjero que expone Ellis, Andrew, "Historia y política del voto en el extranjero", en Voto en el extranjero..., cit., pp. 53 y ss. 
Es además una cuestión que debe ser abordada de acuerdo a las circunstancias concretas de cada país, en especial teniendo en cuenta el signo y alcance de sus movimientos migratorios, sin que se pueda hablar de un estándar internacionalmente reconocido y tendencialmente obligatorio de su alcance.

En efecto, no existen, con relación a este tema, otros límites internacionales que los derivados del principio de proporcionalidad, aplicables a toda limitación de derechos, de manera que, ni en los estándares del Convenio Europeo de Derechos Humanos ni en los de la Convención Interamericana, los requisitos para el ejercicio del derecho de sufragio se conciben, per se, como restricciones indebidas, sino que simplemente han de estar previstos por la ley, ser necesarios en una sociedad democrática y superar el test de proporcionalidad. El sufragio aparece como un derecho de configuración legal en el que se reconoce un amplio margen de apreciación nacional. ${ }^{4}$

Nos movemos, por tanto, en el campo de las decisiones que deben ser adoptadas a nivel estatal, siendo, además, relativamente infrecuente que la propia Constitución condicione estrechamente las decisiones del legislador.

El legislador debe considerar una serie de factores como el número de nacionales residentes en el extranjero y su concentración en determinadas zonas geográficas, la consolidación de los procedimientos electorales internos, la confianza que genera el funcionamiento de sus autoridades electorales, en particular la asunción no discutida de los resultados electorales, y un último factor un tanto más difuso, el grado de influencia real en los asuntos políticos que los nacionales están dispuestos a reconocer a los que lo han abandonado permanentemente el país sin perder su nacionalidad, aunque con frecuencia adquiriendo al mismo tiempo una tercera.

Factores, todos ellos, que provocan que la decisión a adoptar no resulte sencilla y que debamos reconocer como punto de partida que encierra importantes problemas a alguno de los cuales nos referiremos a continuación.

${ }^{4}$ Véase García Roca, Javier y Dalla Via, Alberto, "Los derechos políticos y electorales. Un orden público democrático", en García Roca et al. (coords.), El diálogo entre los Sistemas Europeo y Americano de Derechos Humanos, Pamplona, Civitas, 2012, pp. 221 y ss. 


\section{Algunos problemas teóricos y prácticos derivados de su reconocimiento}

El primero de los problemas puede ser denominado "la paradoja de la modernidad contradictoria", expresión con la que se alude al hecho de que un ordenamiento que pretenda recoger las nuevas tendencias en la extensión del derecho de sufragio se encuentra sometido a una irresoluble contradicción interna, en especial si, como ocurre con frecuencia en un mundo progresivamente más globalizado es, al mismo tiempo, productor y receptor de migrantes.

Por una parte, a partir de la década de los noventa, el sufragio de los residentes en el extranjero tiende a presentarse como una exigencia de madurez y modernidad de nuestras democracias, que, se afirma, no serían completas si ignorásemos los derechos políticos de un grupo cuantitativamente pequeño de personas que, de una u otra manera, desarrollan sus funciones oficiales, por ejemplo diplomáticas, de cooperación internacional o de mantenimiento de la paz, en el exterior $y$, sobre todo, si prescindiésemos de cientos de miles o millones de trabajadores migrantes que colaboran con sus remesas a nuestro bienestar. Sólo reconociendo su derecho de sufragio se les restaura el ejercicio de su ciudadanía.

Se trata, conviene destacarlo, de un movimiento que surge en países de signos y alcances migratorios muy distintos, de manera que aparece en algunos tradicionalmente receptores de inmigración y que tienen en consecuencia un tanto por ciento relativamente pequeño de ciudadanos en el exterior, como Estados Unidos, Alemania o Francia, junto a otros de signo radicalmente distinto como la República Dominicana o México, o incluso en aquellos que han modificado el signo histórico de sus migraciones, como Italia o España. Presentan también diferencias sensibles desde el punto de vista socioeconómico y de desarrollo de sus instituciones democráticas.

Sin embargo, en paralelo, este movimiento ha convivido en el tiempo con la superación del dualismo de la Revolución francesa entre hombre y ciudadano, de manera que los derechos fundamentales se predican de todas las personas y no sólo de los ciudadanos. En el campo del sufragio esto significa su reconocimiento progresivamente mayor a los extranjeros residentes estables, inicialmente solo para las elecciones locales, pero progresivamente para todas ellas. 
Es cierto que este movimiento nace en Estados con alto grado de desarrollo como los países nórdicos o Nueva Zelanda, pero no es posible establecer una relación entre desarrollo y reconocimiento del sufragio de los extranjeros en la medida en que alguno de los más ricos del mundo siguen reservando toda expresión del sufragio a sus nacionales, como Estados Unidos o Alemania, y por el contrario, otros productores de emigración, como Ecuador o Bolivia lo han introducido en sus ordenamientos. ${ }^{5}$

Es inevitable apreciar un cierto grado de contradicción entre ambos postulados de la modernidad. No parece coherente potenciar ambas cosas al mismo tiempo. O afirmamos que la residencia y no la nacionalidad es la premisa del ejercicio del derecho, en cuyo caso no fomentamos el sufragio en el extranjero de nuestros nacionales, por lo menos de aquellos cuya ausencia no puede ser considerada temporal o, por el contrario, consideramos que el criterio sigue siendo la nacionalidad, en cuyo caso es coherente establecer un sufragio de los nacionales en el extranjero mientras la conserven, pero no facilitar el de los extranjeros por continuada y plenamente integrada que resulte su residencia.

Paradoja que puede agravarse cuando el ordenamiento jurídico condiciona el reconocimiento del derecho de sufragio de los extranjeros a la reciprocidad (artículo 13.2 de la Constitución Española) y, exponencialmente cuando reconoce la posibilidad de doble nacionalidad (artículos 11.3 de la Constitución Española y 37 de la mexicana)

La pregunta es si un Estado puede y debe al mismo tiempo procurar que sus nacionales residentes en el exterior ejerzan los derechos políticos en los países en los que residen, y, en paralelo, organizar costosos y estadísticamente escasamente utilizados mecanismos para que puedan seguir votando en su país de origen. Pedir que se actúe de esa forma es tanto como exigir que se rompa el principio esencial del Estado democrático, una persona un voto, aquel que provoca, con Valadés y Carpizo, que se pueda tener dos nacionalidades pero no se deba tener dos ciudadanías. ${ }^{6}$

5 Véase Santolaya, Pablo, Nacionalidad, extranjería y derecho de sufragio, Madrid, Centro de Estudios Políticos y Constitucionales, 2007, y Santolaya, Pablo y Díaz Crego, María, El sufragio de los extranjeros. Un estudio de derecho comparado, Madrid, Centro de Estudios Políticos y Constitucionales, 2008.

6 Véase Valadés, Diego, Consideraciones constitucionales sobre el voto mexicano en el exterior; también Carpizo, Jorge, El voto de los mexicanos en el extranjero, contextos peligros y propuestas, ambos en http://biblio.juridicas.unam.mx/libros/4/1995/4.pdf. 
Y puestos a no romper ese dogma angular del Estado democrático, quizá tenga razón el maestro Carpizo cuando señala que la auténtica reivindicación no consiste en que puedan votar a autoridades cuyas decisiones no les pueden beneficiar ni perjudicar, sino conseguir el sufragio en el país en el que residen. ${ }^{7}$

Llamaremos al segundo de los problemas teórico-prácticos del reconocimiento del sufragio en el exterior "la paradoja antidialéctica" en cuanto que, aparentemente, solicitamos de los procedimientos de sufragio en el extranjero que contradiga uno de los principios de esa ciencia, la ley de la transición de la cantidad a la cualidad, que constata que los cambios cuantitativos generan cambios cualitativos. Trataré de explicarme:

Generalmente un país sólo se preocupa por poner en marcha un procedimiento generalizado de sufragio desde el extranjero cuando cuenta con un número significativo de migrantes. En caso contrario, se limita, en el mejor de los casos, a regularlo para determinados colectivos acotados, por ejemplo representantes oficiales en el exterior.

Es decir que el reconocimiento generalizado del derecho sólo se produce cuando responde a una demanda al menos teórica de un número significativo de nacionales. Precisamente porque son muchos es importante conocer a quienes otorgan su representación y, consecuentemente, hemos de admitir su capacidad de incidencia en el proceso, es decir de alterar, incluso drásticamente, el resultado electoral “interno".

Teóricamente todas las normativas y autoridades electorales pretenden que el mecanismo sea utilizado por el mayor número posible de residentes en el exterior, y la clave de su éxito o fracaso - como es patente en los juicios emitidos sobre el funcionamiento de los mecanismos mexicanos tanto en 2006 como en 2012 - suele hacerse coincidir con el tanto por ciento de los que han ejercido el derecho, lo que por otra parte, hace que el coste por sufragio sea aceptable en una operación que resulta siempre muy onerosa.

De manera que si uno preguntase cuántos votos se pretende recibir del extranjero la respuesta sería que el más alto posible, el más cercano al de los residentes en el exterior, lo que lo convertiría en un modelo exitoso y sostenible.

7 Valadés, op. cit., p. 50. 
No se suele sin embargo añadir un inconfesable sobreentendido. Cuantos más votos mejor... siempre que no cambien el sentido de la elección, es decir, expresado de forma un tanto brusca, que resulten, en realidad irrelevantes a efectos de los resultados, porque en el fondo no sería pacífico que precisamente esos votos originaran un vuelco de los resultados en el interior, por ejemplo en la elección de un presidente de la República.

Con un factor añadido, el voto en el exterior, en general, no sólo es que se ejerza en menor medida que en el interior, sino que se hace de forma distinta. Sus resultados tienden a no ser los mismos, por lo que si son lo suficientemente numerosos pueden originar el problema señalado. Por ejemplo entre el electorado residente en el extranjero español se ha demostrado una tendencia a reflejar con algunos años de retraso las alternancias del electorado nacional, por lo que no es en absoluto extraño que quien gana en el interior no lo haga (todavía) entre los residentes en el extranjero. Lo mismo parece haber sucedido en las recientes elecciones presidenciales francesas de 2012, en las que al contrario de lo que sucedió en Francia, el ex presidente Sarkozy se impuso de forma clara entre los residentes en el extranjero. ${ }^{8}$

Quizá una de las consecuencias de esta inconfesable paradoja es que, como demuestra numéricamente Navarro, hay una evidencia global de la enorme, cuando no abismal, diferencia entre las estimaciones o proyecciones de los presuntamente beneficiados por este tipo de sufragio y los que llegan a registrarse como electores y a ejercer posteriormente su derecho de sufragio. ${ }^{9}$

El tercero de los problemas, muy relacionado con el anterior, podemos denominarlo "la paradoja de la pérdida de legitimidad" y consiste en señalar que la organización del sufragio en el exterior que pretende lograr una mayor legitimación del sistema electoral puede originar el

8 En la segunda vuelta de las elecciones el 53.05\% de los electores en el exterior votaron a Sarkozy cuando en Francia obtuvo el $48.36 \%$. Por el contrario Hollande obtuvo el 51.64\% de los votos “internos" pero sólo el $48.36 \%$ de los provenientes del extranjero. Resulta especialmente interesante la rapidez con la que los electores en el extranjero recibieron en esta ocasión el cambio en el país, porque apenas un mes más tarde en las elecciones legislativas, la izquierda se impuso en 8 de las 11 circunscripciones.

9 Navarro, Carlos, "El voto en el extranjero", en Nohlen et al. (coords.), Tratado de derecho electoral comparado de América Latina, 2a. ed., Instituto Interamericano de Derechos Humanos, 2007, aporta cifras que demuestran que la realidad no mejora sustancialmente en aquellos sistemas en los que el registro es legalmente obligatorio, como ocurre en Argentina o Perú. 
efecto radicalmente distinto en la medida en que no se desarrolle de manera adecuada. Los déficits procedimentales en el sufragio en el exterior provocan, con extremada facilidad, críticas globales sobre el sistema y la capacidad de actuar neutral y eficazmente de sus autoridades electorales.

En este sentido conviene empezar por recordar un dato que he expuesto con detalle hace ya algunos años y que parece constituir una de las normas universales de funcionamiento de los sistemas electorales. $^{10}$

Se trata de constatar que las críticas al sistema electoral suelen ser perfectamente asimilables sin merma de legitimidad. Así se puede discutir sobre el mayor o menor grado de proporcionalidad del sistema, la adecuación de una u otra fórmula matemática de conversión de sufragios en términos de representación, las ventajas o desventajas del voto abierto o bloqueado, la necesidad de organizar un sufragio paritario y un largo etcétera. Nada de ello incide sin embargo de forma grave en la esencia misma del sistema, su capacidad de generar legitimación, y de todo ello es prueba evidente el sistema británico, tan discutido como consolidado. Se acepta incluso de forma universal que la mediación característica de los sistemas electorales no es neutral ni químicamente pura, sino que suele favorecer a los partidos mayoritarios que son, no lo olvidemos, los que hacen las leyes electorales.

Por el contrario, las críticas a los procedimientos electorales y a la actividad de las autoridades electorales resultan altamente corrosivas para el conjunto del sistema, que difícilmente puede sobrevivir si es objeto de dudas fundadas sobre la corrección del censo, la realización del escrutinio o la manipulación del sufragio, y en definitiva sobre la actuación no neutral de las autoridades electorales en estos y otros momentos claves del procedimiento electoral. Cuando esto sucede se está poniendo en duda la limpieza misma del proceso, su carácter democrático y representativo. Y el riesgo de que se produzcan este tipo de acusaciones se multiplica exponencialmente cuando se organiza el sufragio de los residentes en el extranjero.

Trataré de explicar esa afirmación. Para empezar creo que todos podemos estar de acuerdo en que las posibilidades de actuación eficaz de un ordenamiento jurídico y de las autoridades destinadas a imple-

10 Santolaya, Pablo, Manual de procedimiento electoral, 4a. ed., Madrid, Ministerio del Interior, 1999. 
mentarlo se reducen drásticamente cuando es aplicado en el extranjero. No es por tanto ni siquiera concebible un procedimiento teórico que cuente con las mismas garantías en el exterior que en el interior. Por definición cualquier sufragio en el extranjero es menos garantista de unas elecciones libres y justas que los desarrollados en el interior, de manera que resulta inevitable, como han puesto de manifiesto Nohlen y Grotz, que la instrumentalización del voto en el extranjero presente grandes problemas técnico-administrativos que pueden interferir en otras características relevantes del sufrago universal, específicamente con el principio de elecciones libres. ${ }^{11}$

El problema es cuántas garantías menos está dispuesta a admitir la opinión pública sin poner en duda la legitimidad de todo el proceso, lo que depende en primer lugar del número de votos del que estemos hablando, de su relevancia global o no, pero también de la cautela, en ocasiones razonable, con la que se analiza cualquier actividad de una autoridad electoral, de lo que en otro trabajo he denominado "la escala de desconfianza" sobre los organismos electorales. ${ }^{12}$ En un sentido similar Navarro ${ }^{13}$ señala que en la medida en que el régimen electoral cuente con un alto grado de confianza y credibilidad es más sencillo introducir el sufrago en el extranjero, e inversamente que la decisión se complica cuanto más controvertido resulte internamente.

Sin embargo con ello se está poniendo clamorosamente sobre la mesa el riesgo, la paradoja, de introducir este tipo de mecanismos en democracias aún no plenamente indiscutidas en cuanto a sus mecanismos electorales, que suelen coincidir con las que poseen mayor tanto por ciento de residentes permanentes en el extranjero.

En la medida en que rebajemos los requerimientos del voto libre, igual y secreto podremos estar ampliando el número de personas que lo ejerzan desde el exterior, pero, al mismo tiempo, inevitablemente, estamos aumentando las posibilidades de un sufragio no libre, gestionado por los partidos políticos, clientelista. Y con ello puede ocurrir que se ponga en entredicho la legitimidad del conjunto del sistema,

11 Nohlen, Dieter y Grotz, Florián, "Marco legal y panorama de la legislación estatal", en Voto en el Extranjero..., cit., p. 76.

12 Santolaya, Pablo, "El modelo español de administración electoral”, en Biglino, Paloma y Delgado, Luis (coords.), La resolución de los conflictos electorales. Un análisis comparado, Madrid, Centro de Estudios Políticos y Constitucionales, 2010, pp. 21 y ss.

13 Navarro, Carlos, "Los derechos políticos y el voto en el extranjero de los trabajadores migrantes", en Voto en el Extranjero..., cit., p. 190. 
teniendo en cuenta, con Thompson, "los problemas administrativos o retrasos que presenta el voto en el extranjero se perciben como actos deliberados de fraude por parte del gobierno o incluso del organismo electoral". ${ }^{14}$ En definitiva, un relativamente pequeño beneficio en términos de número de votos en el extranjero puede tener efectos devastadores si con ello se pone en duda la credibilidad del proceso.

\section{Un breve panorama de derecho comparado con algunas cuestiones a considerar}

De acuerdo al Panorama comparado del voto en el extranjero elaborado por ACE Electoral Knowledge Network, son (abril de 2008) 115 los Estados que establecen algún tipo de mecanismo que hace posible el sufragio desde el extranjero. ${ }^{15}$ Esta cifra significa aproximadamente el 58\% de los miembros de la ONU y una proporción aún mayor de los países cuyas elecciones pueden ser consideradas libres y justas de acuerdo a los estándares internacionales y que son en realidad los únicos a considerar en sus alternativas técnicas al problema.

Un conjunto de países con relación al cual es difícil obtener algún tipo de característica común al incluir muchos de los que poseen un grado más elevado de desarrollo económico e institucional (gran parte de los componentes de la Unión Europea, o Canadá) con alguno de los menos desarrollados del planeta en África y Asia (como Ruanda o Afganistán), con un número relativamente pequeño de emigrantes en el extranjero y por el contrario con tantos por cientos de migrantes que en ocasiones superan el $25 \%$ de los nacionales del país, (Republica Dominicana), presidencialistas y parlamentarios, monarquías y repúblicas, con fuerte tradición de utilización de los mecanismos de democracia directa, como Suiza, o en los que esas prácticas resultan virtualmente desconocidas, centralizados y descentralizados...

Presentan requisitos y condicionantes muy diferentes entre sí, incluso si nos referimos a ámbitos geográficos relativamente homo-

14 Thompson, Judy, "La instrumentación del voto en el extranjero", en Voto en el Extranjero..., cit., p. 121.

15 Disponible en http://aceproject.org/ace-es/topics/va/vaa/onePage. Muchos de los datos comparados se han obtenido de esa fuente, junto a la del Manual de IDEA Internacional reiteradamente citado. 
géneos como la Unión Europea, que hacen que sólo de forma muy aproximativa podamos aplicar la categoría común "países que reconocen el derecho de sufragio en el extranjero", a realidades que abarcan desde Irlanda —donde sólo se reconoce a los diplomáticos y militares en misión oficial- o Suecia donde la duración máxima de la ausencia es de 10 años, hasta otros como España en el que ese derecho es de la totalidad de los que conservan la nacionalidad, aunque no hayan residido nunca en territorio español, y, hasta muy recientemente, para la totalidad de las elecciones.

No resulta posible por tanto identificar un modelo ideal de voto desde el extranjero que pueda ser aplicado como paradigma universal, y en este sentido resulta particularmente acertada la admonición de Nohlen y Grotz de que, en el supuesto de que se opte por reconocerlo, cada país debe diseñarlo de acuerdo a las condiciones de su contexto particular y procurando minimizar los riesgos colaterales que tal decisión provoca. ${ }^{16}$

Precisamente por ello el panorama de derecho comparado que se ofrece no puede ser una interminable descripción de soluciones concretas adoptadas por los distintos países, sino que más bien se ha optado por exponer alguna de las cuestiones que deben ser contestadas a la hora de regular esta materia, jalonándolas de referencias a los ordenamientos que las han adoptado.

\section{Tipo de elecciones a las que se aplica}

Una de las primeras decisiones que se debe abordar es el tipo de elecciones al que se aplicarán la posibilidad de sufragio en el extranjero. Se trata de uno de los aspectos en el que el estudio de derecho comparado ofrece datos más contundentes. Aparentemente tanto por razones teóricas como de tipo práctico sólo en las elecciones nacionales, presidenciales o parlamentarias.

Es por el contrario excepcional abrir esa posibilidad a elecciones subnacionales, ni siquiera en los Estados federales en los que adquieren singular importancia, y menos aún a las elecciones locales. Son también infrecuentes los países que reconocen la posibilidad de participar mediante instrumentos de democracia directa.

16 Nohlen, Dieter y Grotz, Florián, “Marco legal...”, cit., p. 86. 
De acuerdo al informe de ACE sólo hay seis países en el mundo que lo admiten para todas las categorías de procesos electorales y referendos que se celebran en el país, pero el listado está formado por singularidades, al tratarse de una posibilidad teórica y escasamente desarrollada en la práctica como los Estados Unidos en lo que se refiere a cualquier proceso distinto a las presidenciales, afectar a un número muy reducido de personal oficial (Irlanda) o tratarse de países escasamente significativos y aún cuestionables en cuanto al carácter libre y justo de sus procesos electorales.

\section{Extensión personal}

Algunos países consideran que solamente las personas que desarrollan algún tipo de actividad oficial en el extranjero, como los diplomáticos o los militares, cuya estancia por otra parte es de carácter normalmente temporal y que conservan indudables vínculos con su nación, pueden ejercer el derecho de sufragio desde el extranjero, negándoselo a los que han abandonado de forma tendencialmente estable el país.

En la Unión Europea sólo un país, Irlanda, presenta esa especificidad, lo que quizá pueda razonarse precisa y paradójicamente en el alto número histórico de inmigrantes irlandeses al extranjero, en particular a la Gran Bretaña y los Estados Unidos, y el temor a que su sufragio condicionara la toma de decisiones "internas".

Al margen del caso irlandés y del de la India que quizá encierre temores similares, el manual de ACE individualiza un total de 11 países más que establecen este restringido reconocimiento del sufragio desde el extranjero, ninguno de los cuales, se encuentran en el ámbito geográfico iberoamericano, aunque de acuerdo a los datos ofrecidos por Navarro, éste parece ser el caso de Puerto Rico, que lo hace sólo para las personas que desempeñan funciones oficiales en el extranjero. ${ }^{17}$

\section{Extensión temporal}

Requiere mayor atención la decisión en torno a si el derecho a participar directamente o por medio de representantes en los asuntos pú-

17 Navarro, Carlos, Tratado de derecho electoral..., cit., p. 233. 
blicos debe ser permanente en tanto se conserve la nacionalidad de origen, o por el contrario pueden exigirse vínculos adicionales a la nacionalidad. ${ }^{18}$

Desde un punto de vista teórico no hay duda que el condicionamiento del derecho a la conservación de vínculos adicionales con el país de origen supera la más estricta aplicación del principio de proporcionalidad. También creo que quizá la forma menos problemática de medirla es la duración de la estancia en el extranjero.

De manera que nos encontramos ante un requisito relativamente frecuente dentro de la Unión Europea, ya que existe al menos en Gran Bretaña, un máximo de 15 años; Alemania, 10 que no se aplican dentro de la Unión Europea, y Suecia 10 con posibilidad de petición de una prórroga durante otros 10 . También en algunas otras de las democracias más consolidadas del mundo, incluso con plazos menores, como en Australia con 6, Canadá con 5 y Nueva Zelanda con 3. Por el contrario, no existe, hasta donde tengo conocimiento, ningún país en Iberoamérica que haya establecido requisitos de este tipo.

Todavía más razonable resultaría la exclusión de este derecho de aquellas personas que, por haber adquirido una doble nacionalidad, pueden ejercer sus derechos políticos en el Estado en que residen. Sin embargo, ni el Manual de IDEA ni el de ACE citan al respecto un solo ejemplo en el mundo de una regulación en este sentido, aunque al parecer en Panamá se produce una suspensión de los derechos inherentes a la ciudadanía cuando los organismos electorales tienen conocimiento de que un residente en el extranjero ha adquirido otra nacionalidad. ${ }^{19}$

\section{Extensión territorial}

Existen algunos ejemplos en derecho comparado, en especial en el ámbito iberoamericano, de lo que podemos denominar, con Navarro, ${ }^{20}$ un enfoque selectivo en cuanto a la cobertura geográfica del derecho

${ }_{18}$ Véase Carpizo, Jorge, El voto de los mexicanos en el extranjero, contextos peligros $y$ propuestas y el ya citado de Valadés, Jorge, Consideraciones constitucionales, cit.

${ }_{19}$ El dato proviene de la intervención de Sharon Sinclaire en el panel sobre "Voto desde el extranjero" en la IV Conferencia Iberoamericana sobre Justicia Electoral. El Salvador, 3 y 4 de septiembre de 2012.

${ }^{20}$ Los derechos políticos, cit., p. 192. 
de sufragio de los residentes en el exterior, de manera que se organizan procesos electorales destinados no a la totalidad de ellos, sino exclusivamente a los que residen en las zonas donde se ubica el mayor tanto por ciento de población migrante, que además, y por razones evidentes, cuenta con una estructura consular e incluso de organizaciones de los propios migrantes, que eventualmente pueden colaborar en el proceso.

Se pretende con ello concentrar esfuerzos organizativos y presupuestarios y resulta un sistema en mi opinión particularmente adecuado para los países que presentan un alto grado de concentración en sus destinos migratorios. Permite también una extensión progresiva y gradual, en la medida en que, una vez consolidada, se suelen ir ampliando en cada proceso electoral a otras zonas geográficas.

En este sentido cabe destacar la experiencia de la República Dominicana, ${ }^{21}$ que en 2001 optó por un establecimiento progresivo de centros de registro en las ciudades y países donde residan el mayor número de dominicanos y se cuente con estructura consular o diplomática. Ese mismo año se abrió la Oficina para el Registro de los Electores en el Exterior (OPREE) de Nueva York, a la que paulatinamente se añadieron las correspondientes a otras ciudades de Estados Unidos, Canadá, España, Puerto Rico y Venezuela. En 2012 se habían abierto también en Panamá, Italia y Suiza, de manera que en la actualidad abarcan un altísimo tanto por ciento de sus migrantes.

Menos exitosa parece ser la experiencia al respecto en Honduras. La Ley de 2001 estableció, de forma provisional, que en las elecciones presidenciales de noviembre de ese año solamente sería posible votar en las oficinas consulares de seis ciudades de Estados Unidos en las que se concentraban el mayor número de residentes hondureños. La situación no evolucionó en las elecciones correspondientes a 2006, en las que incluso finalmente no pudieron efectuarse en la totalidad de las previstas. Posteriormente se ha realizado alguna extensión del mapa original, de manera que, por ejemplo, los residentes en España pueden hacerlo a partir de 2009, sin embargo el modelo no parece haber funcionado adecuadamente. ${ }^{22}$

${ }^{21}$ Véase, para un estudio detallado, Arias Núñez, Luis, "República Dominicana. Acuerdo político para responder a las demandas de voto en el exterior", en Voto en el Extranjero..., cit., p. 195.

22 Véase Hernández Cruz, Jacobo, "Honduras: Los efectos de una decisión basada en cálculos políticos”, en Voto en el Extranjero..., cit., pp. 139 y ss. 
También ha optado por este enfoque progresivo Bolivia, que inicialmente lo ha utilizado sólo en las embajadas y consulados de cuatro países (Argentina, Estados Unidos, Brasil y España), si bien tiene prevista una problemática generalización de cara a las elecciones de 2014 a la totalidad de los países en los que posee representación diplomática, más de 100, lo que puede resultar problemático y sobrepasar la capacidad operativa de su Tribunal Supremo Electoral. ${ }^{23}$

Podemos considerar una variable de este procedimiento el existente en Brasil, en el que para acreditar una sección electoral en el exterior es necesario que se hayan inscrito un mínimo de electores, treinta en concreto, exigencia que, de ser trasladada al ordenamiento mexicano, excluiría un nutrido grupo de países desde los que se han ejercido el voto en las elecciones en $2012 .^{24}$

\section{El requisito de la inscripción}

Prácticamente todos los sistemas de votación en el extranjero exigen, de una u otra manera, una expresa petición en tiempo hábil del ejercicio del derecho de sufragio por parte del ciudadano, aunque existe alguna excepción, incluso en el ámbito Iberoamericano, como es el caso de Panamá.

Estamos ante lo que se denomina "voto rogado", de forma que la administración electoral no actúa de oficio para facilitar su ejercicio, sino que espera una expresa petición del interesado. Las razones por las que se opta por la expresa petición y no por considerar que todos los inscritos como residentes en una determinada sección consular van a ejercer en ella su voto, tienen que ver con una pluralidad de factores.

El primero de ellos, al que ya nos hemos referido, es que este tipo de votación se suele aplicar exclusivamente a los procedimientos electorales de alcance nacional, de manera que el ciudadano sigue adscrito,

${ }^{23}$ En ese sentido se expresó el presidente del Tribunal Supremo Electoral de Bolivia, Wilfredo Obando Rojas, en su intervención en el panel sobre "Voto desde el extranjero" en la IV Conferencia Iberoamericana sobre Justicia Electora, El Salvador, 3 y 4 de agosto de 2012.

${ }^{24}$ Véase para el caso brasileño Calderon Chelius, Leticia, "El voto obligatorio y el renovado interés por los electores en el extranjero", en Voto en el Extranjero..., cit., pp. 135 y ss. 
normalmente a su municipio de origen o a una determinada circunscripción como la capital de la nación, en los restantes. La petición de sufragio en el exterior se configura así como una excepción temporal para un concreto proceso.

Pero incluso en aquellos sistemas en los que es posible el ejercicio del derecho desde el extranjero en todas las elecciones, hay también razones que aconsejan su configuración como rogado para garantizar el carácter personal del sufragio, y, entre ellas, la imposibilidad de que los registros consulares tengan el mismo grado de actualización que los del interior del país, por ejemplo a la hora de recoger las bajas o cambios de domicilio. De esta manera la petición se convierte, al mismo tiempo, en un instrumento de depuración del censo de residentes en el extranjero, absolutamente aconsejable desde el punto de vista del carácter democrático del proceso.

El problema no es por tanto la necesaria inscripción, sino la posibilidad de realizar todas las operaciones previas al ejercicio del derecho de sufragio ante las propias autoridades diplomáticas o consulares, o la necesidad de que se efectúe en territorio nacional, ya que entonces se convierte en un trámite en muchas ocasiones insuperable, e incide muy negativamente en el tanto por ciento de ciudadanos que ejercen el sufragio.

México es, en este sentido, una excepción, ya que incluso la República Dominicana que hasta 2006 lo efectuaba de esa manera, modificó su normativa para hacerlo posible en las oficinas diplomáticas y consulares. Una situación intermedia la encontramos en la legislación brasileña en la que los ciudadanos realizan sus peticiones en el extranjero, y son las delegaciones diplomáticas las que se encargan de gestionarlas ante las autoridades electorales nacionales. Pero sin duda el procedimiento más adecuado es el que habilita a las propias autoridades en el exterior para realizar todos los trámites previos a la votación.

\section{El procedimiento de votación}

Desde el punto de vista teórico son cuatro las posibles formas de organización del procedimiento de votación de los ciudadanos residentes en el exterior. Pueden hacerlo personalmente en las respectivas oficinas diplomáticas y consulares, por correo, normalmente certificado dirigido a las autoridades electorales en su país, mediante una expresa 
representación o delegación en un ciudadano que resida en el país de votación y ejerza su derecho de voto en la misma circunscripción o utilizando algún tipo de sufragio electrónico, bien por internet, mail o fax.

Son también frecuentes los modelos mixtos, en los que se ofrece a los electores la alternativa de hacerlo, por ejemplo personalmente en los recintos diplomáticos o por correo.

Sin embargo el voto por delegación es absolutamente excepcional, en la medida en que son muchos los ordenamientos que predican constitucionalmente el carácter "personal" del sufragio, de manera que las dos únicas experiencias que podemos considerar relativamente relevantes son los casos francés y belga y en ningún de ellos es la única ni la más extendida forma de ejercicio.

Lo que genéricamente denominamos voto electrónico es todavía una experiencia relativamente marginal, de resultados al menos dudosos, quizá con la muy reciente, y aún pendiente de evaluar en su totalidad, experiencia de las elecciones presidenciales francesas de 2012, y salvo en algunos ejemplos no significativos, casi todos Estados insulares polinésicos, no constituye el único procedimiento posible de votación. Tampoco parece que existan ejemplos de voto por Internet pero en entornos controlados y que ofrezcan determinadas garantías como los consulados o embajadas. ${ }^{25}$

En definitiva, los dos medios más empleados para el ejercicio del derecho de sufragio son el voto personal ante embajadas o consulados y el voto por correspondencia. El primero de ellos resulta el más extendido tanto en derecho comparado ( 54 casos frente a 25 como procedimiento único de votación de acuerdo al Informe de ACE) como en Iberoamérica, donde los dos únicos ejemplos de voto postal son México y Puerto Rico, al que cabría añadir el caso de Panamá que compatibiliza este procedimiento con la posibilidad de emitirlo por Internet.

Desde el punto de vista de las garantías del derecho de sufragio, de su carácter libre, personal y secreto, no hay ninguna duda que resulta más aconsejable el voto presencial en los recintos diplomáticos que el

25 De acuerdo al Informe de ACE el voto por Internet sólo existe como procedimiento único de votación desde el extranjero en Mauricio, Nauru, Togo y Vanuatu. La inexistencia de voto electrónico en entornos controlados de embajadas o consulados es puesta de manifiesto por Braun, Nadja, "El voto electrónico y el voto en el extranjero", en Voto en el Extranjero..., cit., pp. 227 y ss. 
voto postal, difícilmente controlable en cuanto a sus garantías en todo caso, pero en especial si se desarrolla en el exterior, cuyas autoridades no pueden estar sometidas al mismo régimen disciplinario e incluso penal que las que actúan en territorio nacional.

Tiene, como único inconveniente, que depende de las estructuras diplomáticas, de la red de consulados y embajadas de las que disponga el país, de manera que por tupida que ésta resulte, siempre existirán ciudadanos que residan lejos de los posibles centros de votación.

Es precisamente ese afán de universalizar el derecho el que lleva en ocasiones a optar por el sufragio por correspondencia, teóricamente al alcance de los ciudadanos en todo el mundo. Sin embargo lo que se gana en extensión personal se puede perder en el carácter democrático del sufragio, en especial si, como ha sucedido en México ponemos en marcha prácticas o interpretaciones legales destinados a su extensión pero problemáticas desde el punto de vista de sus garantías, como la no necesidad de fijar un domicilio de recepción, pudiendo tener tal carácter un apartado postal. Por todo ello, en especial si contamos con una migración altamente concentrada en determinadas zonas geográficas puede no tratarse de la mejor opción posible.

\section{Las autoridades encargadas del proceso}

Constituye uno de los nudos centrales de la organización del sufragio en el extranjero, en especial en aquellos modelos no gubernamentalizados de administración electoral, como son prácticamente todos los Iberoamericanos.

El punto de partida inevitable para analizar este aspecto del problema es que ni los procedimientos ni las propias autoridades electorales están diseñados para actuar en el exterior, y cuando lo hacen, no pueden estructuralmente hacerlo con la misma eficacia que en territorio nacional en importantes aspectos sometidos a su control como, por ejemplo, los medios de comunicación, los actos de propaganda electoral, la financiación y un largo etcétera.

El problema adquiere una dimensión mayor en aquellos ordenamientos en los que el Poder Ejecutivo tiene un papel menor en los procesos, ya que las únicas autoridades nacionales acostumbradas a actuar en el extranjero son la estructura de consulados y embajadas dependientes del Poder Ejecutivo, y en determinados ordenamientos 
la actuación en estos procedimientos de cualquier autoridad ajena a las electorales es vista con profunda desconfianza.

Tampoco hemos podido constatar ejemplos relevantes de colaboración internacional de autoridades extranjeras, gubernativas o electorales, en este tipo de procesos. Probablemente se trata de una materia muy sensible y cercana a la soberanía nacional para que se pueda dar por bueno que las elecciones presidenciales de los mexicanos residentes en Estados Unidos sean organizadas y controladas por las autoridades electorales americanas, posibilidad sobre la que ironizaba Carpizo.

No faltan, sin embargo, ejemplos concretos de colaboración menor. Por ejemplo las elecciones de muchos países iberoamericanos se celebran en España en espacios públicos cedidos por las autoridades españolas, con protección oficial de la policía, y en ocasiones con medios electorales como urnas o cabinas cedidas por la administración electoral española. No es fácil, sin embargo, pensar en una colaboración que vaya mucho más allá de la prestación de este tipo de auxilio.

En estas circunstancias la administración electoral tiene que estar de alguna manera en condiciones de actuar en el exterior. En caso contrario, es decir, si insiste en que la mayor parte de las actividades se realicen en territorio nacional, presupuesto que parece ser el presente en la normativa mexicana, y que es probablemente su pecado original, estaremos dificultando considerablemente el derecho de sufragio, y, al mismo tiempo, no habremos resuelto la posibilidad de fraudes en el momento clave de la emisión del sufragio.

Las autoridades electorales deben estar, en consecuencia, preparadas para actuar en el exterior, bien directamente o bien mediante una estrecha colaboración con el área responsable de las relaciones internacionales del Poder Ejecutivo. Para ello debe optar o por abrir delegaciones específicas adscritas a las embajadas y consulados, como en el modelo de la República Dominicana o actuar a través del personal diplomático sometido en esa función a su autoridad, como ocurre en el brasileño.

Ambas soluciones son teóricamente posibles y la opción por una y otra depende del grado de confianza en la neutralidad de las autoridades diplomáticas, y también de que el sufragio sea una opción general o circunscrita a algunas jurisdicciones coincidentes con las de mayor número de residentes nacionales. En este último caso es probablemente aconsejable el desplazamiento o establecimiento de específicas unidades dependientes de las autoridades electorales. 
En cualquier caso, la peor opción posible parece ser la de intentar una gestión centralizada nacional de todos los momentos del proceso desarrollado en el exterior.

\section{La previsión de circunscripciones especiales}

También es preciso hacer referencia a los sistemas, presentes sobre todo en los países del sur de Europa como Francia, Italia y Portugal, pero también en el ámbito iberoamericano, en Colombia, Panamá y más recientemente Ecuador, y en su conjunto en una docena de Estados, en los que se ha optado por reservar un tanto por ciento de escaños de la o las cámaras legislativas a los residentes en el extranjero.

La proporción de estos escaños oscila entre el 0.6\% de Colombia y el $8.3 \%$ de Cabo Verde, organizando a ese respecto circunscripciones supranacionales en las que los electores ejercerán su derecho y erigirán sus propios representantes (por ejemplo en el caso Italiano 12, divididos en cuatro circunscripciones, Europa, Norte y Centro América, Sudamérica, y resto del mundo a razón de un mínimo inicial de 1 diputado y 1 senador y el resto atendiendo a la población nacional en la circunscripción)

Con ello se pretende lograr una mayor integración de los residentes en el extranjero en la política nacional al contar con sus propios representantes, pero, al mismo tiempo, inevitablemente, se multiplican los problemas prácticos y organizativos de este tipo de sufragio, al extenderse a momentos previos como los de selección y presentación de candidatos, y hacer necesaria una campaña electoral específica, especialmente problemática en su control, por ejemplo en cuanto a sus límites materiales o financieros.

No resulta en consecuencia una opción aconsejable, salvo quizá en aquellos ordenamientos que tengan ya una notable y exitosa experiencia en la gestión de elecciones desde el exterior.

\section{9. ...y, en cualquier caso, una baja participación}

Todos los estudios realizados con relación al voto de los residentes en el extranjero ponen de manifiesto que, sea cual sea el procedimiento elegido, por perfeccionado que éste resulte, e incluso en los supuestos 
de voto obligatorio, el voto de los residentes en el extranjero es ejercido por un tanto por ciento de electores significativamente menor al que lo hacen en territorio nacional, en el mejor de los casos siempre inferior al 50\%, pero con numerosos ejemplos de participación residual o simbólica, como en el caso de Brasil, ${ }^{26}$ donde a pesar de tratarse de un sufragio obligatorio y de la apreciable estructura electoral del país, no supera el 5\% de los potenciales electores, cifra que, a pesar de todo, resulta extraordinariamente más elevada que las logradas en el caso mexicano tanto en 2006 como en 2012.

Datos que deberían hacer reflexionar sobre la incidencia real de una decisión política de este tipo. Incluso en el mejor modelo posible, los resultados de forma inevitable parecen destinados a no alcanzar las expectativas.

Quizá se deba a límites estructurales del modelo y resulte sencillamente imposible superar determinados umbrales de participación cuando se trata de un universo de ciudadanos integrados en otro país, a pesar de que conserven su nacionalidad de origen, y por tanto relativamente desinteresados de los asuntos públicos nacionales salvo en circunstancias realmente excepcionales, lo que explica, por ejemplo, que la participación en los procesos de transición o en la ratificación mediante referéndum de una nueva Constitución tras un periodo autoritario suela ser, a pesar de todas las dificultades organizativas, mayor.

\section{En particular, el caso español.} La rectificación de un modelo "de máxima generosidad" 27

Hasta fecha reciente, el sufragio de los residentes españoles en el extranjero era considerado un modelo de máxima generosidad y descrito en el Manual de IDEA Internacional como de "voto para todo y para todos" ${ }^{28}$ Sin embargo se ha producido una significativa restric-

${ }^{26}$ Véase el apartado La participación de los electores en el extranjero de el Informe de ACE citado. Para los datos de Brasil: Calderón Chelius, Leticia, "El voto obligatorio...”, cit.

27 La redacción de este apartado ha tenido como base: Santolaya, Pablo, Procedimiento y garantías electorales, Civitas, 2012, próxima publicación.

${ }_{28}$ Lugilde, Anxo, "España, voto en el extranjero para todo y para todos", en Voto en el Extranjero..., cit., pp. 40 y ss. 
ción reciente de este derecho. Analicemos brevemente su alcance y las razones que la han provocado, en la medida en que puede resultar una ilustrativa lección de derecho comparado:

El artículo 31.2 de la Ley Electoral española (LOREG) establece que el censo electoral está compuesto por el censo de los electores residentes en España, y por el censo de los electores residentes-ausentes que viven en el extranjero. El precepto aclara que ningún elector puede figurar simultáneamente en ambos. Hasta la Ley Orgánica 2/2011, los españoles residentes en el extranjero podían votar y ser elegidos en todas las elecciones en nuestro país. Sin embargo la referida reforma contiene a este respecto dos novedades de consideración, ambas en su artículo 75; elimina radicalmente el derecho de los residentes asuntes en las elecciones municipales, y convierte en voto rogado su ejercicio en los demás procesos electorales.

Para analizar esta reforma hay que comenzar por señalar que la exigencia constitucional del reconocimiento legal del ejercicio del derecho de sufragio de los españoles "que se encuentren fuera del territorio español”, prevista en el segundo párrafo del artículo 69.5 de la Constitución, abarca exclusivamente las elecciones al Congreso de los Diputados, de manera que la ley podría pura y sencillamente suprimir su participación en cualquier otro proceso electoral, aunque es cierto que el artículo 42 de la Constitución que ordena al Estado velar por la salvaguardia de los derechos económicos y sociales de los emigrantes puede ser un elemento adicional que avala una interpretación más amplia de su participación en otros procesos electorales.

Sin embargo, desde el inicio de la transición política, en concreto desde el Decreto 3341/1977, del 31 de diciembre, que establece el Censo de los Residentes Ausentes que viven en el extranjero (CERA), estos preceptos se sometieron a un desarrollo claramente favorable a los emigrantes, creando la categoría, evocadora y hasta un punto contradictoria, de residente-ausente a los que la Ley de Bases de Régimen Local reconoce la condición de vecinos exclusivamente a efectos electorales, pero no, por ejemplo, para determinar su población. En paralelo la LOREG reconoció su participación en todos los procesos electorales.

El resultado es que, aunque resulte insólito en términos de derecho comparado, los españoles residentes en el extranjero, han votado y han podido ser elegidos en todas las elecciones de todas las instancias representativas hasta las elecciones locales de 2011. Además la ins- 
cripción en el CERA inicialmente voluntaria y rogada, se convierte de oficio por la LO 3/1995, lo que provoca un incremento importante en su número.

Todavía en 2006 se aprobó la Ley 40, del 14 de diciembre, del Estatuto de la Ciudadanía Española en el Exterior, cuyo artículo 4.1 contiene la imposible afirmación de que los españoles que residan en el exterior tienen derecho a ser electores y elegibles en todos y cada uno de los comicios en las mismas condiciones que la ciudanía residente en el Estado y en 2007 se aprobó la denominada Ley de la Memoria Histórica, que permitió, durante un periodo de dos años, la adquisición de la nacionalidad, y su inmediata y de oficio conversión en electores, a los hijos de padres o madre españoles de origen y a los nietos de quienes perdieron o tuvieron que renunciar a la nacionalidad como consecuencia del exilio.

El brusco giro producido por la Ley 2/2011 puede ser explicado por la suma de una pluralidad de factores:

El primero de ellos es el imparable crecimiento del número de residentes ausentes, en ocasiones alejados en dos generaciones de los municipios en los que votan. De acuerdo a las cifras que ofrece Delgado-Iribarren, ${ }^{29}$ el CERA se multiplicó por 10 entre 1987 y 2008, pasando de 118894 electores a 1205 149, de manera que se convirtieron en decisivos para otorgar escaños, por ejemplo en las elecciones al Parlamento Gallego de 2009 o en el Parlamento Europeo en las elecciones del mismo año, o, aún de forma más patente, condicionando la formación de gobierno, en las elecciones asturianas en 2012.

El segundo es que durante la IX legislatura se realizó una intensa política de tratados que han permitido el reconocimiento del derecho de sufragio en nuestro país a los ciudadanos de un considerable número de países, rompiendo una inercia de falta de desarrollo, excepto para los comunitarios, del artículo 13.2 de la Constitución. Estos tratados deben constitucionalmente respetar el principio de reciprocidad. Mantener la ficción de la residencia ausencia para el ejercicio de sus derechos democráticos no es que ya no resulte obligado, sino que parece contradictorio con uno de los elementos esenciales del propio Estado democrático, el principio de una persona un voto.

29 "El voto de los españoles residentes en el exterior: problemas actuales y alternativas de reforma”, en Pascua Mateo, Fabio (dir.), Estado democrático y elecciones libres: cuestiones fundamentales de derecho electoral, Madrid, Civitas, 2010, pp. 115 y ss. 
Sin embargo el argumento decisivo es, en mi opinión, el convencimiento de los partidos políticos de que los procedimientos de votación en el extranjero no reúnen el mismo grado de garantía, por ejemplo en lo referente a la actualización del Censo, ni, sobre todo, del voto por correo, que los existentes en territorio nacional, y que los riesgos de una cierta gestión de los sufragios a través de "agentes electorales" hacen aconsejable su restricción, en especial en el supuesto de elecciones municipales, en los que, por el tamaño reducido de la circunscripción, puede resultar de mayor eficacia esos intentos de manipulación.

Por ello la Ley 2/2011 al margen de la modificación del artículo 31.2 , contiene otros preceptos en los que se trata de paliar las posibilidades de manipulación de los sufragios de los residentes ausentes en las demás elecciones. Entre ellas conviene resaltar la limitación de las peticiones de cambios de circunscripción que sólo se admitirán si existe causa suficiente y justificada para ello, no teniéndose en cuenta las producidas en el año anterior a la convocatoria de las elecciones (artículo 36.1 y 2)

También la existencia de un nuevo procedimiento de depósito del voto en urnas establecidas en los consulados (artículo 75) en lo que parece ser una especie de situación intermedia entre el voto por correo y el auténtico voto en sedes diplomáticas, quizá no del todo definido en cuanto a sus términos de ejercicio en la norma, pero que bien regulado, puede constituir una opción a analizar cuando lo que se pretende es mantener el voto por correo, pero eliminando alguno de sus inconvenientes, como el coste del envío a cargo del ciudadano, o asegurar su recepción tempestiva.

\section{La respuesta del ordenamiento jurídico mexicano}

\section{Las circunstancias fácticas}

Entre los elementos fácticos ${ }^{30}$ que deben ser valorados a la hora de regular el sufragio de los mexicanos residentes en el extranjero conviene

${ }^{30}$ Navarro, Carlos, Los derechos políticos..., cit.; Navarro, Carlos y Carrillo, Manuel, "Cuidando la identidad..., cit.; González Ulloa Aguirre, Pablo Armando, Analizando y comparando las cifras. Votos 2006 y 2012, http://www.iniciativaciudadana.org.mx/obser- 
comenzar por señalar que México cuenta con un elevado número de ciudadanos en edad de votar residentes en el extranjero. Las cifras son muy variables, pero se calcula que en 1998 era de aproximadamente 10 millones, es decir el 15\% de los entonces registrados para votar. En 2006 esa cifra ascendía aproximadamente a 11 millones y en 2012 se estima que son 11 millones quinientos mil. Es por tanto un colectivo que potencialmente puede condicionar los resultados de cualquier proceso electoral mexicano.

De ellos, un tanto por ciento insólito en derecho comparado, que se valora en todas las fuentes consultadas en más del 95\%, se encuentran concentrados en un solo país, los Estados Unidos de América, y un elevadísimo tanto por ciento, superior al 90\% en los estados de California, Texas, Illinois, Arizona, Florida y la ciudad de Nueva York. Por razones evidentes en esos lugares hay una muy amplia red consular, de manera que, por ejemplo, en Texas existen once oficinas consulares.

Un considerable tanto por ciento se encuentran en situación administrativa de irregularidad, lo que si bien es cierto, como apunta Navarro, suele provocar reticencias a la hora de acercarse a sus propias autoridades a realizar cualquier tipo de gestión y en particular a confesar el domicilio, ${ }^{31}$ en mi opinión esas dificultades se multiplican si lo que deben realizar es cualquier tipo de actividad ante las autoridades del país en el que residen ilegalmente, incluido el mero contacto con el correo ante el que tienen que aportar su domicilio a efectos de certificación, y, en la práctica, imposibilita cualquier gestión que tengan que realizar personalmente en su propio país, al no poderse arriesgar a volver a cruzar la frontera.

\section{Alcance de la reforma constitucional}

El marco jurídico que ha permitido el ejercicio del derecho de sufragio de los mexicanos en el extranjero arranca de la reforma del artículo 36 de la Constitución en 1996. Hasta ese momento los ciudadanos ejercían su derecho-deber de sufragio "en el distrito electoral que les co-

vatorioelectoralbinacional/; Favela Herrera, Adriana Margarita, "Hacia la elección presidencial de 2012: aproximación a una reforma legal para la instrumentación del voto de los mexicanos en el exterior", Revista Mexicana de Derecho Electoral, núm. 2, juliodiciembre de 2012; Carpizo, Jorge, El voto de los mexicanos..., cit.

31 Navarro, Carlos, “Los derechos políticos...”, cit., p. 188. 
rresponda" lo que había sido interpretado como una imposibilidad radical de sufragio a los residentes en el extranjero, en el contexto de un ordenamiento constitucional que, por otra parte, y hasta el 20 de marzo de 1998, excluía radicalmente la posibilidad de doble nacionalidad, ya que su artículo 32 establecía la pérdida de la nacionalidad mexicana de las personas que voluntariamente adquirían una tercera. ${ }^{32}$

Es interesante destacar el hecho de que la reforma de 1996 se limita a introducir en el texto constitucional que los ciudadanos mexicanos tienen la obligación de "votar en las elecciones populares en las elecciones y en la consultas populares en los términos que señale la ley".

Precepto que no puede ser entendido sino como una amplia remisión a la ley como instrumento configurador del alcance del derecho, de manera que si bien es cierto que en la génesis de la reforma se encuentra la voluntad de reconocer el sufragio a los residentes en el extranjero, sin embargo considero que cualquiera de los sistemas de derecho comparado a los que nos hemos referido sería aplicable al caso mexicano, es decir que podría limitarse, en los términos utilizados a lo largo de este trabajo, desde el punto de vista de su extensión personal, temporal y territorial, sin incidir en inconstitucionalidad, porque, dicho con Favela Herrera, ${ }^{33}$ el artículo 36 de la Constitución, no reconoce de manera explícita el derecho a votar en el extranjero, sino que se limitó a remover un requisito de ejercicio precisamente en un distrito en territorio nacional.

Lo que significa una amplia libertad de configuración para el legislador, que puede optar en cada momento, por el régimen que considera más adecuado para satisfacer ese derecho, operación en la que puede ampliar, pero también restringir o condicionar el modelo anterior, que no puede considerarse sometido a principio alguno de irreversibilidad jurídica, y ello con independencia de las dificultades políticas que una operación de este tipo podría provocar, que disminuirían si existe una apreciación generalizada del incorrecto funcionamiento del modelo utilizado.

32 La interrelación dialéctica entre ambos preceptos constitucionales y sus respectivas reformas es brillantemente expuesta por Valadés, Diego, Consideraciones constitucionales..., cit.

33 Favela Herrera, Adriana Margarita, “Hacia la elección presidencial de 2012..., cit. 


\section{Breve exposición crítica de los artículos 313 a 339 del Cofipe}

El proceso para la elaboración de las disposiciones referentes al voto de los mexicanos residentes en el extranjero del Cofipe fue extremadamente complejo, con una duración de casi 10 años y la actuación de una Comisión Independiente de especialistas que integró el Instituto Federal Electoral, que presentó su informe a finales de 1998. Sin embargo la reforma legal del Cofipe no se produjo hasta junio de 2005, de manera que se empleó por primera vez en las elecciones de 2006 y se ha vuelto a utilizar, sin modificación relevantes, en las elecciones de 2012.

Las características esenciales del procedimiento pueden ser resumidas de acuerdo a las categorías empleadas en este trabajo en los siguientes términos:

- Se ha limitado a las elecciones presidenciales.

- Se ha optado por una extensión universal del derecho; todos los mexicanos residentes en el exterior, sin límite temporal por la duración de la ausencia ni de doble nacionalidad.

- Tampoco hay ningún tipo de limitación por razones territoriales. Es un derecho de todos los mexicanos residentes en el extranjero, con independencia de la dimensión de la comunidad mexicana en ese país.

- Se ha hecho depender de un requisito de inscripción, estar en posesión de una documentación, la denominada credencial para votar con fotografía, que sólo es posible obtener en México.

- Se ha optado por una modalidad de voto, por correo, insólito en la tradición electoral mexicana y con muy escasos precedentes en el ámbito Iberoamericano. El voto se recepciona, escruta y contabiliza en México.

- En general, existe una fuerte centralización del proceso en el Instituto Federal Electoral, y, en paralelo, un escaso o nulo aprovechamiento de la estructura diplomática o consular, salvo para una función secundaria como es la obtención de un impreso, que podría ser descargado de la red, probablemente derivado de la configuración de la administración electoral mexicana como un modelo de suma desconfianza al Ejecutivo.

- Este control centralizado provoca la configuración de otros elementos como por ejemplo el derivado de la prohibición absoluta 
de campaña electoral en el exterior al resultar imposible la actuación del IFE, en términos ni siquiera remotamente similares a la incisiva vigilancia de los medios de comunicación que ha establecido en el interior del país.

\section{La necesidad de reformar el procedimiento}

A la vista del diseño institucional elegido y de las circunstancias fácticas expuestas: ¿puede considerarse satisfactoria la experiencia mexicana?

La respuesta más generalizada en la doctrina y en la opinión pública mexicana parece ser de signo negativo, y se basa, sobre todo, en el enorme esfuerzo institucional y presupuestario realizado y los resultados extremadamente pobres en términos de número de sufragios efectivamente emitidos. Menos extendidas son, sin embargo, las críticas a la relajación de determinados controles en garantía del carácter libre y personal del sufragio, comprensibles en aras a su simplificación, pero que no dejan de ser perfectamente posibles desde el punto de vista teórico.

De manera que, de acuerdo a las cifras ofrecidas por Navarro, Carrillo y González Ulloa, en 2006 se calculaba que existían 11 millones de mexicanos en el extranjero, de los que estaban dotados de la credencial para votar aproximadamente 4.2 millones. Después de una inversión económica de 21.8 millones de dólares se registraron un total de 40876 mexicanos y llegaron a ejercer su derecho de voto 32632 , un tanto por ciento insignificante que implicó, además, que, en términos económicos, cada sufragio tuviera para el Estado mexicano un coste de aproximadamente 668 dólares estadounidenses.

Cifras que apenas han mejorado en las recientes elecciones de 2012, de manera que si bien es cierto que se ha producido un aumento en el número de personas registradas válidamente para votar, de en torno al $8 \%$ y que el presupuesto económico se redujo en cerca de un $23 \%$ el total de los sufragios finalmente emitidos, de acuerdo al Informe del Instituto Federal Electoral sobre el Voto de los Mexicanos Residentes en el Extranjero 2012, fueron 40737 , que en forma alguna hace variar el juicio sobre su cuantía y coste.

Las críticas se centran, especialmente, en el hecho de que para el registro y posterior votación se exija un documento oficial que sólo 
puede ser obtenido mediante la solicitud personal en una oficina en México, la denominada credencial para votar con fotografía, de la que carece un tanto por ciento muy importante, aunque progresivamente menor de la población residente en el extranjero, no estando legalmente facultado el IFE para emitirla fuera del territorio nacional.

También en la necesidad de utilizar el correo certificado, en el doble sentido de revelar un domicilio ante las autoridades postales, lo que puede dificultar su ejercicio para migrantes en situación de irregularidad y por el costo de cada envío.

Por último se acusa al procedimiento, en ocasiones de forma genérica, de ser excesivamente complejo y se propugna una igualmente inespecífica simplificación.

El propio Instituto Federal Electoral elaboró, a raíz de las elecciones de 2006 un Libro Blanco sobre el voto de los mexicanos en el extranjero, emitiendo una serie de recomendaciones tanto puramente administrativas como de reforma del marco legal, de las que se han aprobado, para las elecciones de 2012, algunas de ellas, de carácter relativamente menor, como la asunción del coste postal del envío por el IFE, la no solicitud de comprobante del domicilio para participar en la votación, y el establecimiento de un plazo para aclarar inconsistencias para disminuir la invalidación de solicitudes ${ }^{34}$ que, aparentemente, no han contribuido significativamente al mejor funcionamiento del sistema.

Y todo ello, además, con una crítica generalizada al coste del sufragio en el extranjero, que, efectivamente, contabilizado por voto emitido resulta difícil de justificar.

Sin embargo la mayoría de las críticas realizadas hasta el momento son intrasistemáticas, es decir que no ponen en duda ni la existencia del voto desde el extranjero, ni en realidad los elementos esenciales del procedimiento vigente, sino que se mueven en el campo de las posibles mejoras o adaptaciones para hacerlo más eficaz y, en la medida de lo posible, con un coste económico más contenido.

${ }^{34}$ Véase sobre estas recomendaciones: González Ulloa Aguirre, Pablo Armando, Analizando y comparando las cifras..., cit. 


\section{Conclusión: algunos elementos para su reforma basados en la experiencia del derecho comparado}

El elemento clave para el perfeccionamiento del procedimiento del voto desde el exterior de los mexicanos residentes en el extranjero consiste, precisamente, en la necesidad de trasladar alguna de las operaciones que el Instituto Federal Electoral realiza en el interior del país, de manera que se efectúen en los lugares de residencia de los migrantes.

Es, en primer lugar evidente que ni siquiera resulta concebible un buen procedimiento de voto en el extranjero organizado completamente al margen de la representación diplomática de ese país, y, sin embargo, la lectura del procedimiento regulado en el Cofipe, parece que es eso precisamente lo que consciente pretende, al prescindir, casi de forma absoluta, de la existencia de embajadas y consulados mexicanos.

La única referencia a estas legaciones contenida entre los artículos 313 al 339 la encontramos en el artículo 318.2, en el que se señala que "Las sedes diplomáticas de México en el extranjero contarán con los formatos a que se refiere el párrafo anterior (para solicitar la inscripción en la lista nominal de electores) para que estén a disposición de los ciudadanos mexicanos. El Instituto celebrará con la Secretaría de Relaciones Exteriores los acuerdos correspondientes".

No se puede dejar pasar por alto que lo que se encomienda a esas sedes diplomáticas es exclusivamente, el depósito de un formulario, que inicia el procedimiento y que como tal formulario podría perfectamente descargarse de Internet, como ocurre en otros muchos ordenamientos jurídicos. Es por tanto un procedimiento virtualmente organizado al margen de la representación diplomática.

$Y$ es evidente que este punto de partida debe ser modificado. No se trata en absoluto de entregar la organización y el control de los procesos electorales en el exterior a la Secretaría de Relaciones Exteriores, sino de reconocer que el voto desde el extranjero debe también, en cierta medida, organizarse desde las sedes diplomáticas de ese país en el exterior.

A la hora de plasmar esa realidad existen como hemos señalado, tendencialmente dos modelos, el primero de ellos, presente por ejemplo en Brasil, es colocar al personal diplomático encargado de esas 
funciones bajo la dependencia de las autoridades electorales. El segundo, probablemente mucho más adecuado al diseño institucional mexicano, consiste en establecer oficinas de representación del propio Instituto Federal Electoral en las sedes diplomáticas y consulares.

¿Qué tipo de operaciones electorales podrían realizar esas oficinas electorales en el extranjero?

Podrían, en primer lugar, subsanar una de las carencias unánimemente resaltada por los comentaristas del procedimiento y encargarse de la emisión de las credenciales para votar de los residentes bajo su jurisdicción.

Podrían también desarrollar una suerte de función asesora de los ciudadanos residentes en el exterior sobre todos los extremos del procedimiento.

Podrían organizar algún tipo de actividades, por ejemplo contactos entre los representantes de los candidatos y los ciudadanos o incluso debates entre ellos, que, sin vulnerar la prohibición de proselitismo fuera del país presente en el Cofipe, permitiera un cierto flujo de información controlada sobre las elecciones hacia las comunidades migrantes.

Podría pensarse en la implementación de mecanismos que permitieran actuar a esas oficinas como depositarias de votos, al modo como se establece en España en el artículo 75 de la ley electoral, de manera que los electores pueden entregarlos personalmente o enviar su voto por correo a embajadas y consulados durante un determinado periodo, siendo estas delegaciones las encargadas de su custodia y envío en tiempo y forma a las autoridades electorales para su recuento. Evitaríamos con ello varios de los problemas presentes en el actual procedimiento, el recelo de los migrantes irregulares para facilitar su domicilio a las autoridades postales, el coste del correo certificado y las deficiencias de algunos sistemas postales.

Pero llegados a este punto podríamos dar un paso más adelante y plantearnos la posibilidad de hacer compatible el actual procedimiento de voto por correspondencia, con un voto presencial en determinadas sedes diplomáticas de manera progresiva, un procedimiento potencialmente mucho menos conflictivo desde el punto de vista del sufragio libre y secreto, y más acorde a la tradición mexicana e iberoamericana.

El electorado mexicano en el extranjero presenta además una característica a la que hemos hecho referencia en varias ocasiones y que 
parece hacerlo particularmente idóneo para esta solución; su extraordinaria concentración.

En las elecciones presidenciales de 2012 el IFE contabilizó un total de 40737 sufragios procedentes de 92 países. Sin embargo de ellos 29348 eran de residentes en Estados Unidos y junto a los de Canadá, España, Francia y Alemania emitieron un total de 36103, el 86.6\% del total. Por el contrario fueron 38 los países en los que el número de mexicanos que ejercieron su derecho de sufragio fue inferior a 10 .

La pregunta a efectuar es si, en esas condiciones, México debe empeñarse en mantener el actual modelo universal de voto por correspondencia, o debe hacerlo compatible y coexistente con la progresiva extensión del sufragio presencial, comenzando obviamente por aquellas zonas que concentran un mayor número de residentes mexicanos en el extranjero.

Y en mi opinión la respuesta es clara. Una buena estrategia de reforma en la organización del sufragio en el extranjero debería ir encaminada a las reformas legales y administrativas necesarias para que el Instituto Federal Electoral, en el horizonte de las elecciones presidenciales de 2018, eligiendo las jurisdicciones correspondientes a la distribución de las sedes diplomáticas del Estado mexicano, correspondientes a los mayores núcleos de población migrante, sobre todo en Estados Unidos, pero también probablemente en Canadá, España, Francia y Alemania, fuera estableciendo Oficinas de Voto en el Exterior directamente bajo su dependencia, aunque en estrecha colaboración con la Secretaría de Relaciones Exteriores, que pudieran realizar la mayor parte de las operaciones electorales, desde la documentación de los electores hasta la emisión y el recuento del sufragio.

Procedimiento, que, al menos de forma transitoria, debería ser compatible con el mantenimiento del sistema actual de voto por correspondencia en la mayor parte de los países del mundo que no cuentan con un número suficiente de residentes mexicanos. E incluso con relación a ellos podría pensarse en medidas que, manteniendo el sufragio por correspondencia, mejore alguno de los procedimientos actuales, como por ejemplo la posibilidad de que se depositen esos votos en las sedes diplomáticas a los solos efectos del traslado a territorio nacional. También, paulatinamente y con las debidas garantías a abrir la posibilidad de utilizar excepcionalmente algún tipo de sufragio por Internet.

Diseño que, obviamente, debe partir de un criterio claro y absolutamente objetivo, basado, por ejemplo, en el número de residentes, 
como sucede en otros ordenamientos, para evitar de raíz cualquier acusación de manipulación a la hora de adoptar la decisión de los países que van a utilizar uno y otro procedimiento.

Por último considero que en esta operación es más importante la consolidación de resultados del nuevo modelo que la rapidez en la sustitución progresiva del voto por correspondencia por el voto presencial, de manera que el IFE debería realizar una cuidadosa planificación a largo plazo, y en estrecha colaboración con la Secretaría de Relaciones Exteriores acerca de las sedes idóneas y las condiciones de una operación que sólo gradualmente sustituiría en su totalidad al actual modelo de voto en el extranjero, cuyas limitaciones y necesidad de reforma parecen haber quedado acreditadas. 